\title{
Acyclovir and Transmission of HIV-1 from Persons Infected with HIV-1 and HSV-2
}

\section{Citation}

Celum, C., A. Wald, J.R. Lingappa, A.S. Magaret, R.S. Wang, N. Mugo, A. Mujugira, et al. 2010. "Acyclovir and Transmission of HIV-1 from Persons Infected with HIV-1 and HSV-2." N Engl J Med 362 (5) (February 4): 427-439. doi:10.1056/nejmoa0904849.

\section{Published Version}

doi:10.1056/NEJMoa0904849

\section{Permanent link}

http://nrs.harvard.edu/urn-3:HUL.InstRepos:26718771

\section{Terms of Use}

This article was downloaded from Harvard University's DASH repository, and is made available under the terms and conditions applicable to Other Posted Material, as set forth at http:// nrs.harvard.edu/urn-3:HUL.InstRepos:dash.current.terms-of-use\#LAA

\section{Share Your Story}

The Harvard community has made this article openly available.

Please share how this access benefits you. Submit a story.

\section{Accessibility}


ORIGINAL ARTICLE

\section{Acyclovir and Transmission of HIV-1 from Persons Infected with HIV-1 and HSV-2}

\author{
C. Celum, A. Wald, J.R. Lingappa, A.S. Magaret, R.S. Wang, N. Mugo, A. Mujugira, \\ J.M. Baeten, J.I. Mullins, J.P. Hughes, E.A. Bukusi, C.R. Cohen, E. Katabira, \\ A. Ronald, J. Kiarie, C. Farquhar, G.J. Stewart, J. Makhema, M. Essex, E. Were, \\ K.H. Fife, G. de Bruyn, G.E. Gray, J.A. McIntyre, R. Manongi, S. Kapiga, D. Coetzee, \\ S. Allen, M. Inambao, K. Kayitenkore, E. Karita, W. Kanweka, S. Delany, H. Rees, \\ B. Vwalika, W. Stevens, M.S. Campbell, K.K. Thomas, R.W. Coombs, R. Morrow, \\ W.L.H. Whittington, M.J. McElrath, L. Barnes, R. Ridzon, and L. Corey, \\ for the Partners in Prevention HSV/HIV Transmission Study Team*
}

A BSTRACT

\section{BACKGROUND}

Most persons who are infected with human immunodeficiency virus type 1 (HIV-1) are also infected with herpes simplex virus type 2 (HSV-2), which is frequently reactivated and is associated with increased plasma and genital levels of HIV-1. Therapy to suppress HSV-2 reduces the frequency of reactivation of HSV-2 as well as HIV-1 levels, suggesting that suppression of HSV-2 may reduce the risk of transmission of HIV-1.

\section{METHODS}

We conducted a randomized, placebo-controlled trial of suppressive therapy for HSV-2 (acyclovir at a dose of $400 \mathrm{mg}$ orally twice daily) in couples in which only one of the partners was seropositive for HIV-1 (CD4 count, $\geq 250$ cells per cubic millimeter) and that partner was also infected with HSV-2 and was not taking antiretroviral therapy at the time of enrollment. The primary end point was transmission of HIV-1 to the partner who was not initially infected with HIV-1; linkage of transmissions was assessed by means of genetic sequencing of viruses.

\section{RESULTS}

A total of 3408 couples were enrolled at 14 sites in Africa. Of the partners who were infected with HIV-1, 68\% were women, and the baseline median CD4 count was 462 cells per cubic millimeter. Of 132 HIV-1 seroconversions that occurred after randomization (an incidence of 2.7 per 100 person-years), 84 were linked within couples by viral sequencing: 41 in the acyclovir group and 43 in the placebo group (hazard ratio with acyclovir, $0.92,95 \%$ confidence interval $[\mathrm{CI}], 0.60$ to $1.41 ; \mathrm{P}=0.69)$. Suppression with acyclovir reduced the mean plasma concentration of HIV-1 by $0.25 \log _{10}$ copies per milliliter (95\% CI, 0.22 to $0.29 ; \mathrm{P}<0.001)$ and the occurrence of HSV-2-positive genital ulcers by $73 \%$ (risk ratio, $0.27 ; 95 \% \mathrm{CI}, 0.20$ to 0.36 ; $\mathrm{P}<0.001$ ). A total of $92 \%$ of the partners infected with HIV-1 and $84 \%$ of the partners not infected with HIV-1 remained in the study for 24 months. The level of adherence to the dispensed study drug was $96 \%$. No serious adverse events related to acyclovir were observed.

CONCLUSIONS

Daily acyclovir therapy did not reduce the risk of transmission of HIV-1, despite a reduction in plasma HIV-1 RNA of $0.25 \log _{10}$ copies per milliliter and a $73 \%$ reduction in the occurrence of genital ulcers due to HSV-2. (ClinicalTrials.gov number, NCT00194519.)
The authors' full names, degrees, and affiliations are listed in the Appendix. Address reprint requests to Dr. Celum at the Department of Global Health, University of Washington, Harborview Medical Center, 325 Ninth Ave., Box 359927, Seattle, WA 98104.

*Other members of the Partners in Prevention HSV/HIV Transmission Study Team are listed in the Supplementary Appendix, available with the full text of this article at NEJM.org.

This article (10.1056/NEJMoa0904849) was published on January 20, 2010, at NEJM.org.

N EngIJ Med 2010;362:427-39.

Copyright @) 2010 Massachusetts Medical Society. 
T HE SEROPREVALENCE OF HERPES SIMplex virus type 2 (HSV-2), the most common cause of genital ulcer disease worldwide, is 60 to $90 \%$ in populations with human immunodeficiency virus type 1 (HIV-1). ${ }^{1}$ Clinical manifestations of HSV-2 range from unrecognized or mild genital symptoms in most persons with HIV-1 infection to severe genital ulcer disease in persons with advanced HIV-1 disease. ${ }^{2,3}$ Genital shedding of the herpes simplex virus occurs on up to $30 \%$ of days in persons infected with HIV-1, often when they have no symptoms or observable lesions. ${ }^{4,5}$

Laboratory and epidemiologic studies suggest that HSV-2 may increase the infectiousness of HIV-1. HSV-encoded proteins bind integrated HIV-1 in coinfected cells and directly promote the transcription of HIV-1. ${ }^{6-9}$ In persons who are infected with both HIV-1 and HSV-2, symptomatic and asymptomatic reactivation of HSV-2 has been associated with increased HIV-1 levels in the blood and genital tract. ${ }^{10-13}$ In one study, the risk of transmission of HIV-1 to sexual partners was increased by a factor of 4 among persons with HIV-1 infection who had symptomatic genital ulcer disease, as compared with persons with HIV-1 who did not have genital ulcer disease; the majority of cases of genital ulcer disease were due to HSV-2 infection. ${ }^{14}$

Five randomized clinical trials showed that daily therapy for HSV-2 for 8 to 12 weeks reduced plasma HIV-1 levels by 0.25 to $0.50 \log _{10}$ copies per milliliter. ${ }^{4,5,15-17}$ To evaluate directly whether HSV-2 suppressive therapy could prevent the transmission of HIV-1, we conducted a randomized, double-blind, placebo-controlled trial of acyclovir, administered twice daily, as compared with placebo, among African persons who were infected with both HIV-1 and HSV-2 and their heterosexual partners who were not infected with HIV-1.

\section{METHODS}

STUDY POPULATION

We enrolled heterosexual couples in which only one of the partners was seropositive for HIV-1 and that partner was also infected with HSV-2. Couples were recruited at seven sites in southern Africa (Gaborone, Botswana; Gugulethu, Orange Farm, and Soweto in South Africa; and Kitwe, Lusaka, and Ndola in Zambia) and seven sites in East Africa (Eldoret, Kisumu, Nairobi, and Thika in Kenya;
Kigali, Rwanda; Moshi, Tanzania; and Kampala, Uganda) between November 2004 and April 2007, as previously described. ${ }^{18}$ The inclusion criteria for couples were three or more episodes of vaginal intercourse in the 3 previous months and the intention to remain together for at least 24 months. The inclusion criteria for partners infected with HIV-1 were an age of at least 18 years, seropositivity for HIV-1 and HSV-2, a CD4 count of 250 or more cells per cubic millimeter, no conditions associated with acquired immunodeficiency syndrome, and no current antiretroviral therapy. Exclusion criteria for persons infected with HIV-1 were previous adverse reactions to acyclovir, current receipt of therapy for HSV, persistent genital ulcers, current participation in another study, plans for extended travel, and current pregnancy. Inclusion criteria for partners who were not infected with HIV-1 were an age of at least 18 years and HIV-1 seronegativity; the partners who were not infected with HIV-1 could be eligible whether they were seropositive or seronegative for HSV-2.

The protocol was approved by the University of Washington Human Subjects Review Committee and the ethics review committees at all local and collaborating organizations. All study participants provided written informed consent in English or their local language. The Bill and Melinda Gates Foundation funded the study but did not assume responsibility for review of the protocol. The authors designed the study, wrote the protocol, had full access to the raw data, performed all analyses, wrote the manuscript, and had final responsibility for the decision to submit the manuscript for publication.

\section{ENROLLMENT}

Partners with HIV-1 infection were randomly assigned in a 1:1 ratio to receive acyclovir, at a dose of $400 \mathrm{mg}$ orally twice daily, or matching placebo; a block randomization scheme was used, with stratification according to site with the use of a pseudo-random-number generator. The study drug was manufactured by Ranbaxy Laboratories; matched active and placebo tablets were packaged in bottles that were distributed at monthly visits and were provided for the duration of the couples' participation in the study - up to 24 months. At all visits, participants, individually or as couples, received intensive counseling on risk reduction, were provided with condoms, and received treatment for sexually transmitted infec- 
tions according to World Health Organization guidelines.

\section{FOLLOW-UP}

Visits for partners infected with HIV-1 were scheduled monthly to dispense the study drug or placebo, collect any unused drug from the preceding month, and provide counseling on adherence. Monthly adherence to the assigned treatment was assessed by means of pill counts and self-reporting of $100 \%$ adherence or less than $100 \%$ adherence. Interviews were conducted to obtain information regarding high-risk sexual practices in the previous month and symptoms of genital herpes in the previous 7 days. Participants with genital ulceration that was consistent with genital herpes were given open-label acyclovir at a dose of $400 \mathrm{mg}$ three times daily for 5 days, in addition to the study drug; ulcers were swabbed and the specimens were sent for polymerase-chain-reaction (PCR) testing for HSV.

At quarterly visits, all participants underwent a genital examination, and urine samples were obtained from female participants for pregnancy testing. Women infected with HIV-1 who became pregnant were referred to antenatal clinics for services relating to the prevention of mother-tochild transmission, and the study medication was discontinued until a follow-up pregnancy test was negative. Participants with HIV-1 infection who met national guidelines for the initiation of antiretroviral therapy during the follow-up period were referred to local HIV-1 clinics. Partners who were not infected with HIV-1 were interviewed on a quarterly basis about high-risk sexual practices and symptoms of sexually transmitted infections and underwent antibody testing for HIV-1.

The laboratory procedures have been described previously ${ }^{18}$ and are summarized in the Supplementary Appendix, available with the full text of this article at NEJM.org. Study data were recorded on case-report forms and were submitted electronically to a database (DataFax, Clinical Datafax Systems) at DF/Net Research. All investigators except for one statistician and two data managers remained unaware of the randomization assignments until the completion of the study.

\section{END POINTS}

The primary end point was the acquisition of HIV-1 in partners who had not previously been infected; the diagnosis was made on the basis of a positive HIV-1-antibody test after a previously negative test. For participants who were found to have undergone seroconversion to HIV-1 at the first quarterly visit, plasma samples that had been obtained at the time of enrollment were tested for HIV-1 RNA; if the samples were positive, the couple was excluded from the analyses because HIV-1 infection occurred before randomization.

HIV-1 in the initially uninfected partner was classified as likely to have been acquired from the person's study partner (linked transmission) or likely to have been acquired from someone other than the person's study partner (unlinked transmission); the classification was based on the sequencing of plasma samples from the source partner and the newly infected partner for C2-V3C3 regions of env (and, if needed, p17-p24 regions of gag), phylogenetic analysis, and posterior probability of linkage with the use of pairwise nucleotide distances between sequences (see the Supplementary Appendix). Members of an adjudication committee who were experts in HIV-1 sequencing and were unaware of the treatment assignments reviewed the sequencing data and provided a consensus classification of linkage (see the section on Determination of HIV-1 Transmission Linkage and Fig. 1 in the Supplementary Appendix).

\section{STATISTICAL ANALYSIS}

We estimated that with a sample of 3646 couples who were discordant for HIV-1 serologic status and a follow-up period of 12 months, and with the assumption that $85 \%$ of the transmissions of HIV-1 would be linked, 88 linked transmissions of HIV-1 would occur and the study would have $90 \%$ power to detect a $50 \%$ reduction in the incidence of HIV-1 infection in the acyclovir group as compared with the placebo group (from an estimated incidence of 4.0 per 100 person-years to 2.0 per 100 person-years), at a two-sided type I error rate of 5\%. In December 2005, owing to a rate of enrollment that was slower than that projected, the protocol was modified to call for the enrollment of 3000 couples for up to 24 months of follow-up. A total of $96 \%$ of the partners infected with HIV-1 and $95 \%$ of the partners not infected with HIV-1 consented to participate in the extended follow-up. The study was reviewed by an independent data safety and monitoring board; the statistical analyses were monitored on the basis of the Lan-DeMets group sequential method with O'Brien-Fleming stopping boundaries. ${ }^{19,20}$ 


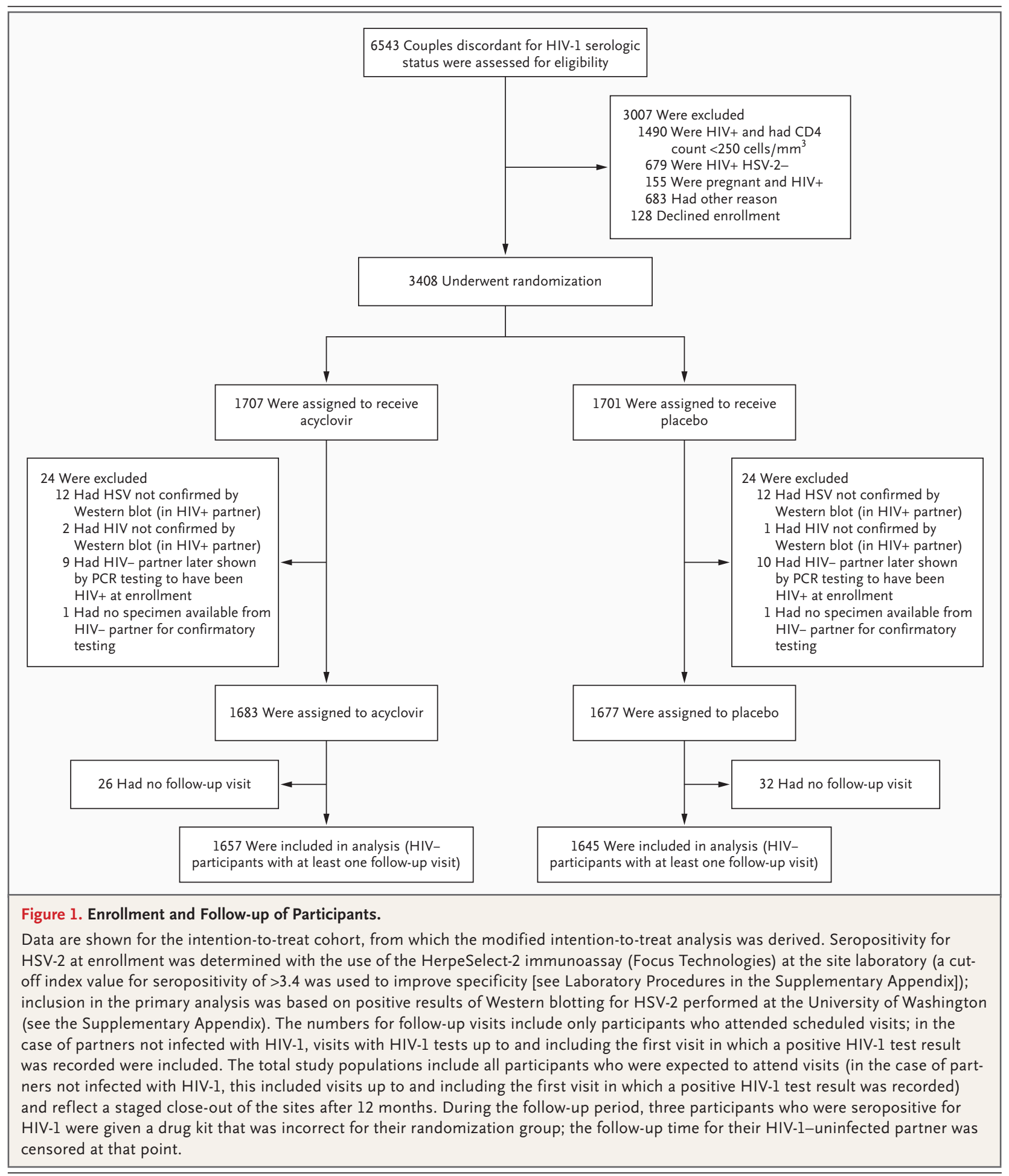

The primary analysis was a modified intentionto-treat analysis of linked transmissions of HIV-1; unlinked transmissions, seroconversions that occurred among men when their female partners who were infected with HIV-1 were pregnant and not taking the study drug, and seroconversions that occurred after the death of the HIV-1-infected partner were excluded. The secondary analysis 
was an intention-to-treat analysis of all HIV-1 transmissions that occurred after randomization, regardless of whether the transmission was linked or whether the HIV-infected person had been exposed to the study drug before seroconversion of his or her partner.

A proportional-hazards regression model, stratified according to site, was used to compare the time to the first positive HIV-1 test between the two study groups, and the Kaplan-Meier method was used to estimate the cumulative probability of infection with HIV-1. Subgroup analyses, defined a priori, were performed with the modified intention-to-treat data set according to the characteristics of the partner who was infected with HIV-1 (sex, presence or absence of genital ulcer disease before enrollment, baseline plasma HIV-1 RNA level, and average level of adherence to the study drug) and the partner who was not infected with HIV-1 (baseline HSV-2 serologic status and circumcision status in the case of men). Tests for differential treatment effects according to these characteristics were based on likelihoodratio comparisons between models with appropriate interaction terms and those without appropriate interaction terms.

A linear mixed-effects model, with a random intercept, was used to evaluate the effect of the intervention on plasma concentrations of HIV-1 ( $\log _{10}$ copies per milliliter) before the initiation of antiretroviral therapy, adjusted for the baseline concentrations of HIV-1. ${ }^{21}$ Generalized estimating equations with Poisson errors and robust variances were used to examine temporal trends in high-risk sexual practices. To evaluate the effect of treatment on genital ulcer disease in partners infected with HIV-1, the numbers of episodes of genital ulcer disease that were observed on examination over the course of the follow-up period were analyzed by log-linear regression, with (log-transformed) duration of follow-up as the offset term in the regression models, negative binomial errors, and robust variances. Reported P values are two-sided and were not adjusted for multiple comparisons.

\section{RESULTS}

\section{STUDY PARTICIPANTS}

A total of 6543 couples who were discordant for HIV-1 serologic status were screened for the study; 3408 of these couples were enrolled. The partners who had HIV-1 infection were randomly assigned to receive acyclovir, at a dose of $400 \mathrm{mg}$ twice daily, or placebo (Fig. 1). After 24 couples in each group were excluded on the basis of confirmatory testing for HIV-1 and HSV-2, the final analysis included 3360 couples (1683 in the acyclovir group and 1677 in the placebo group).

The two groups had similar baseline characteristics (Table 1). In the case of $68 \%$ of the couples, the partner who was infected with HIV-1 was the female partner. A total of $76 \%$ of the couples were married, and $90 \%$ lived together; among the couples living together, the mean duration of the partnership was 5 years. Partners with HIV-1 infection reported a median of six sexual acts with their partner in the month before enrollment. In partners infected with HIV-1, the median baseline CD4 count was 462 cells per cubic millimeter, and median HIV-1 plasma RNA levels were 3.9 $\log _{10}$ copies per milliliter in women and $4.3 \log _{10}$ copies per milliliter in men. At the time of enrollment, $23 \%$ of the partners with HIV-1 infection reported having had symptoms of genital ulcer disease in the previous 3 months, and genital ulcers were observed on examination in 3\% of all HIV-1-infected partners. Among the partners who did not have HIV-1 infection at enrollment, $68 \%$ were seropositive for HSV-2.

\section{FOLLOW-UP, PREGNANCY, AND ADHERENCE TO THE STUDY TREATMENT}

Of the couples who were eligible for 24 months of follow-up, $92 \%$ of the partners infected with HIV- 1 and $84 \%$ of the partners without HIV-1 infection remained in the study for 24 months. Participants who were not infected with HIV-1 accounted for 4868 person-years of follow-up for the assessment of the incidence of HIV-1 infection.

Acyclovir or matching placebo was dispensed at $88 \%$ of the monthly visits. The reasons for not dispensing the study medication included missed visits (in $48 \%$ of cases), pregnancy (36\%, accounting for $4 \%$ of the person-years of follow-up among all participants with HIV-1 infection and 6\% of the person-years of follow-up among female participants, with similar rates in the two groups), death of the HIV-1-infected partner while the partner who was not infected with HIV-1 remained in the study (10\%), and other reasons $(5 \%)$. An assessment of pill counts suggested that participants took $96 \%$ of the dispensed doses. The product of the percentage of drug taken and the percentage of drug dispensed (85\%) provides an overall mea- 
Table 1. Baseline Characteristics of the Participants, According to Study Group.

Partners Who Were Infected
with HIV-1

\section{Partners Who Were Not Infected with HIV-1}

\begin{tabular}{|c|c|c|c|c|}
\hline & $\begin{array}{l}\text { Acyclovir } \\
(\mathrm{N}=1683)\end{array}$ & $\begin{array}{l}\text { Placebo } \\
(\mathrm{N}=1677)\end{array}$ & $\begin{array}{l}\text { Acyclovir } \\
(\mathrm{N}=1683)\end{array}$ & $\begin{array}{l}\text { Placebo } \\
(\mathrm{N}=1677)\end{array}$ \\
\hline \multicolumn{5}{|l|}{ Demographic } \\
\hline Female sex — no. (\%) & $1127(67)$ & $1145(68)$ & $556(33)$ & $532(32)$ \\
\hline \multicolumn{5}{|l|}{ Age - no. (\%) } \\
\hline $18-25 \mathrm{yr}$ & $309(18)$ & $334(20)$ & $243(14)$ & $224(13)$ \\
\hline $26-35 \mathrm{yr}$ & $809(48)$ & $760(45)$ & $730(43)$ & $722(43)$ \\
\hline$\geq 36 \mathrm{yr}$ & $565(34)$ & $583(35)$ & $710(42)$ & $731(44)$ \\
\hline \multicolumn{5}{|l|}{ Education - no. of years of schooling } \\
\hline Median & 8 & 8 & 8 & 8 \\
\hline Interquartile range & $6-11$ & $7-11$ & $7-12$ & $7-11$ \\
\hline Any monthly income - no. (\%) & $619(37)$ & $593(35)$ & $818(49)$ & $828(49)$ \\
\hline Married to study partner - no. (\%)* & $1270(75)$ & $1267(76)$ & $1273(76)$ & $1270(76)$ \\
\hline Living with study partner — no. (\%)* & $1514(90)$ & $1513(90)$ & $1516(90)$ & $1520(91)$ \\
\hline \multicolumn{5}{|l|}{ Duration of partnership - yr* } \\
\hline Median & 5 & 5 & 5 & 5 \\
\hline Interquartile range & $3-10$ & $2-10$ & $3-10$ & $2-10$ \\
\hline \multicolumn{5}{|l|}{ No. of children } \\
\hline Median & 2 & 2 & 2 & 2 \\
\hline Interquartile range & $1-4$ & $1-4$ & $1-4$ & $1-4$ \\
\hline \multicolumn{5}{|l|}{ Sexual activity } \\
\hline \multicolumn{5}{|l|}{ Sexual contacts in previous month - no.* } \\
\hline Median & 5 & 6 & 8 & 9 \\
\hline Interquartile range & $3-10$ & $4-10$ & $4-13$ & $4-13$ \\
\hline \multicolumn{5}{|l|}{$\begin{array}{l}\text { Unprotected sexual acts in previous month } \\
\qquad- \text { no.* }\end{array}$} \\
\hline Median & 0 & 0 & 0 & 0 \\
\hline Interquartile range & $0-1$ & $0-1$ & $0-1$ & $0-1$ \\
\hline $\begin{array}{l}\text { Any unprotected sex in previous month - } \\
\text { no. }(\%)^{*}\end{array}$ & $488(29)$ & $502(30)$ & $501(30)$ & $516(31)$ \\
\hline $\begin{array}{l}\text { Outside sexual partnerships in previous month } \\
\qquad- \text { no./total no. (\%) }\end{array}$ & $59 / 1683(4)$ & $62 / 1677(4)$ & $47 / 814(6)$ & $56 / 798(7)$ \\
\hline \multicolumn{5}{|l|}{ Clinical } \\
\hline \multicolumn{5}{|l|}{ CD4 count - cells $/ \mathrm{mm}^{3}$} \\
\hline Median & 470 & 455 & - & - \\
\hline Interquartile range & $350-637$ & $343-625$ & - & - \\
\hline \multicolumn{5}{|l|}{ Plasma HIV RNA — $\log _{10}$ copies/ml } \\
\hline \multicolumn{5}{|l|}{ Women } \\
\hline Median & 3.96 & 3.92 & - & - \\
\hline Interquartile range & $3.23-4.57$ & $3.20-4.50$ & - & - \\
\hline \multicolumn{5}{|l|}{ Men } \\
\hline Median & 4.31 & 4.35 & - & - \\
\hline Interquartile range & $3.69-4.86$ & $3.63-4.92$ & - & - \\
\hline
\end{tabular}




\begin{tabular}{|c|c|c|c|c|}
\hline \multicolumn{5}{|l|}{ Table 1. (Continued.) } \\
\hline \multirow[t]{2}{*}{ Characteristic } & \multicolumn{2}{|c|}{$\begin{array}{c}\text { Partners Who Were Infected } \\
\text { with HIV-1 }\end{array}$} & \multicolumn{2}{|c|}{$\begin{array}{l}\text { Partners Who Were Not } \\
\text { Infected with HIV-1 }\end{array}$} \\
\hline & $\begin{array}{l}\text { Acyclovir } \\
(N=1683)\end{array}$ & $\begin{array}{l}\text { Placebo } \\
(\mathrm{N}=1677)\end{array}$ & $\begin{array}{l}\text { Acyclovir } \\
(\mathrm{N}=1683)\end{array}$ & $\begin{array}{l}\text { Placebo } \\
(\mathrm{N}=1677)\end{array}$ \\
\hline \multicolumn{5}{|l|}{ Genital ulcer disease - no./total no. (\%) } \\
\hline \multicolumn{5}{|l|}{ Women } \\
\hline $\begin{array}{l}\text { Reported symptoms in previous } \\
3 \text { months }\end{array}$ & $241 / 1127(21)$ & $257 / 1145(22)$ & $9 / 556(2)$ & $6 / 532(1)$ \\
\hline Detected on examination & $38 / 1127(3)$ & $35 / 1145(3)$ & $3 / 556(1)$ & $6 / 532(1)$ \\
\hline \multicolumn{5}{|l|}{ Men } \\
\hline $\begin{array}{l}\text { Reported symptoms in previous } \\
3 \text { months }\end{array}$ & $144 / 556(26)$ & $119 / 532(22)$ & $24 / 1127(2)$ & $21 / 1145(2)$ \\
\hline Detected on examination & $12 / 556(2)$ & $11 / 532(2)$ & $18 / 1127(2)$ & $12 / 1145(1)$ \\
\hline Male circumcision — no./total no. (\%) & $188 / 556(34)$ & $180 / 532(34)$ & $613 / 1127(54)$ & $629 / 1145(55)$ \\
\hline \multicolumn{5}{|c|}{$\begin{array}{l}\text { Any laboratory-confirmed diagnosis of STI - } \\
\text { no./total no. (\%) }\end{array}$} \\
\hline Women & $208 / 1127(18)$ & $217 / 1145$ (19) & $69 / 556(12)$ & $73 / 532(14)$ \\
\hline Men & $43 / 556(8)$ & $39 / 532(7)$ & $117 / 1127(10)$ & $112 / 1145(10)$ \\
\hline
\end{tabular}

* These data were obtained separately from each member of the couple; therefore, responses between the partner infected with HIV-I and the partner not infected with HIV-I sometimes vary.

$\dagger$ Data on outside partnerships during the previous month were obtained for HIV-negative participants only after casereport forms were modified to collect this information.

$\nmid$ Sexually transmitted illness (STI) included syphilis, gonorrhea, chlamydial infection, and trichomoniasis.

sure of study-drug coverage during the follow-up period. Overall, $71 \%$ of participants with HIV-1 infection had at least $90 \%$ coverage, $26 \%$ had less than $90 \%$ coverage, and $3 \%$ had missing data at some visits. Acyclovir was not associated with severe side effects; only one person discontinued acyclovir owing to side effects (headaches).

\section{EFFECT OF ACYCLOVIR ON TRANSMISSION OF HIV-I} Seroconversion to HIV-1 occurred in 132 initially uninfected partners, representing an incidence of 2.7 per 100 person-years $(95 \%$ confidence interval [CI], 2.3 to 3.2) (Fig. 2). A total of 38 transmissions $(29 \%)$ were determined to be not genetically linked, as assessed by viral sequencing, probably reflecting HIV-1 infection from a person other than the study partner; 3 transmissions (2\%) could not be classified. Of 91 genetically linked HIV-1 transmissions (69\%), 6 were excluded because they occurred while women with HIV-1 infection were pregnant and were not taking the study drug, and 1 was excluded because the incorrect drug was dispensed at month 12 . Thus, 84 linked transmissions of HIV-1 were included in the modified intention-to-treat analysis. The incidence of HIV-1 infection, calculated on the basis of linked HIV-1 transmissions, was 1.8 per 100 person-years $(95 \%$ CI, 1.5 to 2.3) overall, 2.5 per 100 person-years (95\% CI, 1.8 to 3.4) for male-to-female transmission, and 1.5 per 100 person-years (95\% CI, 1.1 to 2.0) for female-to-male transmission (hazard ratio for male-to-female transmission as compared with female-to-male transmission, 1.65; 95\% CI, 1.06 to $2.56 ; \mathrm{P}=0.02$ ). The difference between the rate of male-to-female transmission and the rate of female-to-male transmission was attenuated after adjustment for plasma HIV-1 RNA levels (hazard ratio, 1.33; 95\% CI, 0.77 to 2.29).

Of the 84 linked transmissions included in the primary modified intention-to-treat analysis, 41 occurred in the acyclovir group and 43 in the placebo group (hazard ratio with acyclovir, 0.92; 95\% CI, 0.60 to $1.41 ; \mathrm{P}=0.69$ ) (Fig. 3). In the secondary intention-to-treat analysis of all transmissions, 67 occurred in the acyclovir group and 64 in the placebo group (hazard ratio with acyclovir, 0.99 ; 95\% CI, 0.71 to $1.40 ; \mathrm{P}=0.97$ ) (Fig. 2 in the Supplementary Appendix).

In prespecified subgroup analyses performed with the modified intention-to-treat data set, there were no significant differences in the treatment effect according to sex, baseline plasma concen- 


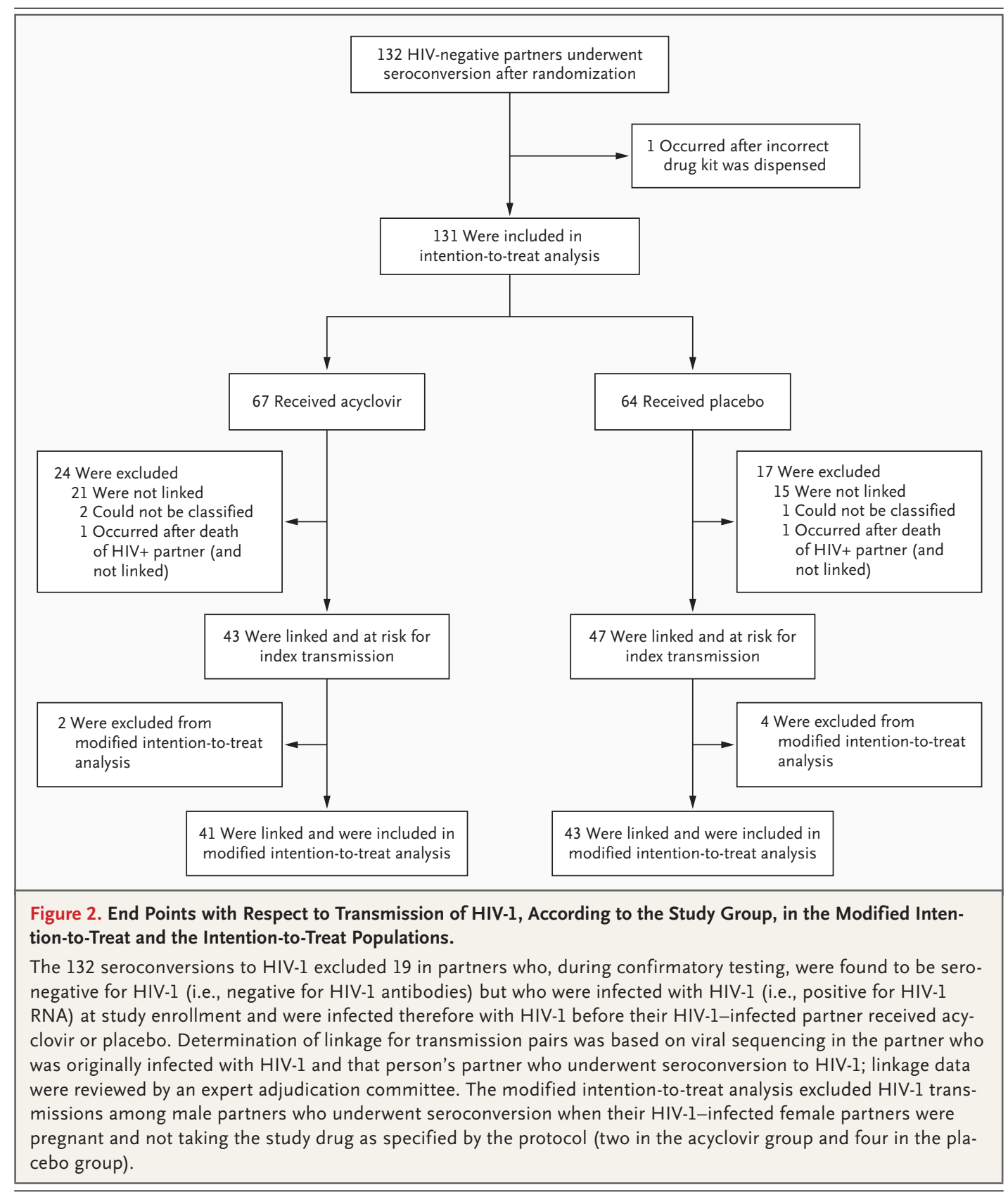

tration of HIV-1, presence or absence of symptoms of genital ulcer disease in the partner with HIV-1 infection in the 3 months before enrollment, level of adherence to the assigned treatment $(<90 \%$ or $\geq 90 \%$ ), baseline HSV-2 serologic status of the partner who was not infected with HIV-1, or circumcision status of male partners who were not infected with HIV-1 (Fig. 4). Partners without HIV-1 infection who were HSV-2-seropositive were at increased risk for acquiring HIV-1, as compared with those who were HSV-2-seronegative (hazard ratio, 2.02; 95\% CI, 1.15 to 3.57), corroborating previous epidemiologic observations. ${ }^{22}$

\section{EFFECT OF ACYCLOVIR IN REDUCING PLASMA HIV-I CONCENTRATIONS}

The mean plasma concentration of HIV-1 during the follow-up period was $0.25 \log _{10}$ copies per milliliter lower in the acyclovir group than in the placebo group (95\% CI, 0.22 to $0.29 ; \mathrm{P}<0.001$ ) 
(Fig. 5). The reductions were similar in men and women $\left(0.30\right.$ and $0.23 \log _{10}$ copies per milliliter, respectively; $\mathrm{P}=0.10$ for the interaction between sex and treatment). An effect of acyclovir was seen across all strata of baseline plasma viral loads. The reduction in plasma HIV-1 concentrations was greater among participants who had baseline plasma HIV-1 concentrations of less than 100,000 copies per milliliter than among those who had baseline concentrations of 100,000 or more copies per milliliter $\left(0.27\right.$ vs. $0.10 \log _{10}$ copies per milliliter; $\mathrm{P}=0.001$ for the difference in acyclovir effect between the two viral-load strata). There was a significant association between the mean rate of adherence to treatment in the previous quarter and the reduction in plasma HIV-1 levels with acyclovir: the reduction in the plasma HIV-1 level was $0.16 \log _{10}$ copies per milliliter when the adherence rate was less than $75 \%, 0.19 \log _{10}$ copies per milliliter when the adherence rate was 75 to $89 \%$, and $0.27 \log _{10}$ copies per milliliter when the adherence rate was $90 \%$ or more $(\mathrm{P}=0.002)$.

\section{PROTECTIVE EFFECT OF ACYCLOVIR AGAINST GENITAL ULCER DISEASE}

A total of 217 episodes of genital ulcer disease were observed over the course of the follow-up period in the acyclovir group, as compared with 550 episodes in the placebo group (risk ratio, 0.39; $95 \%$ CI, 0.32 to $0.48 ; \mathrm{P}<0.001)$. The protective effect of acyclovir against genital ulcer disease was greater when the analysis was restricted to the cases of genital ulcer disease that were positive for HSV DNA as assessed by PCR testing ( 92 in the acyclovir group vs. 336 in the placebo group; risk ratio, 0.27; 95\% CI, 0.20 to $0.36, \mathrm{P}<0.001$ ). There was no significant difference in the protective effect of acyclovir against genital ulcer disease according to sex or status with respect to self-reported symptoms of genital ulcer disease during the 3 months before enrollment $(\mathrm{P}=0.55$ and $\mathrm{P}=0.77$, respectively). Among participants infected with HIV-1, episodic acyclovir therapy was provided at $1.8 \%$ of the visits in the acyclovir group and $4.7 \%$ of the visits in the placebo group.

\section{SERIOUS ADVERSE EVENTS}

A total of 381 serious adverse events, including 77 deaths, were reported; the number of events and the reported causes were similar in the two study groups (see the Supplementary Appendix). No serious adverse events were reported as having been possibly or probably related to acyclovir therapy.

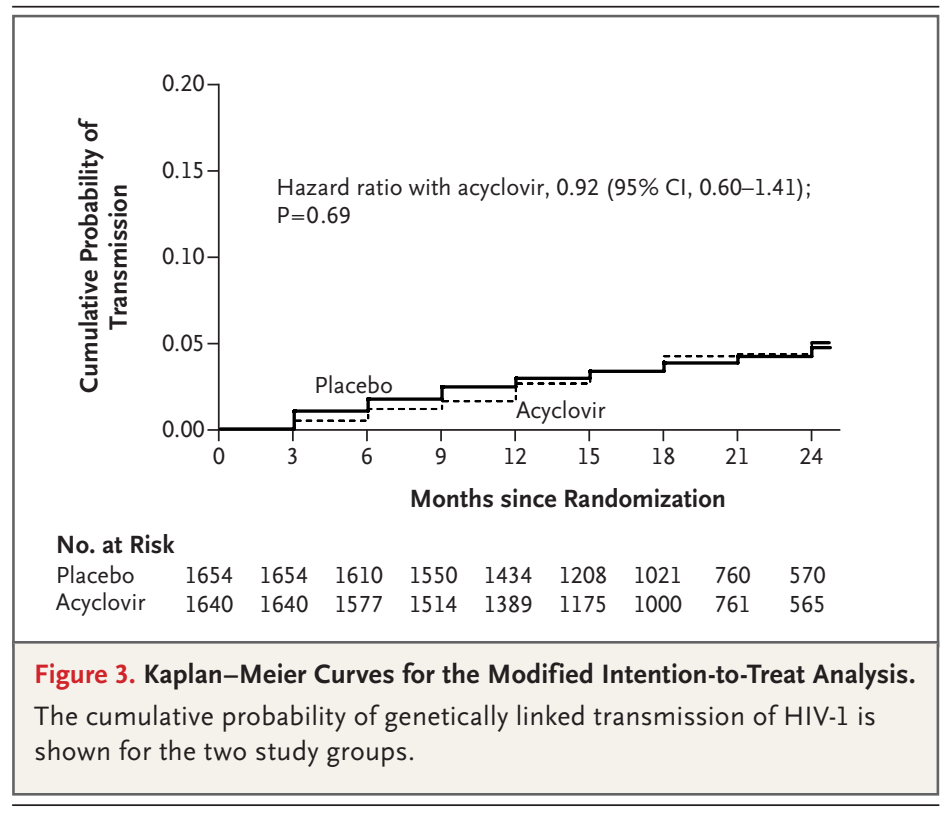

SEXUAL PRACTICES

High-risk sexual practices reported by participants decreased significantly during the follow-up period. A total of $29 \%$ of the partners infected with HIV-1 reported having had unprotected sex during the month before enrollment, as compared with an average of $7 \%$ during the follow-up visits $(\mathrm{P}<0.001)$; the reductions were similar in the two groups $(\mathrm{P}=0.31)$. The proportion of participants not infected with HIV-1 who reported having had sex with a partner other than their study partner increased from $5.4 \%$ at baseline to $15.5 \%$ at 24 months $(\mathrm{P}<0.001)$, with no significant difference between the groups $(\mathrm{P}=0.36)$. Among participants who underwent seroconversion to HIV-1, transmissions that were not genetically linked within the partnership were significantly more common among those who reported having had sex with persons other than their study partner in the 6 months before seroconversion than among those who did not $(79 \%$ vs. $23 \%, \mathrm{P}<0.001)$.

\section{DISCUSSION}

A standard dose of the HSV-2 suppressive drug acyclovir (400 mg twice daily) given for up to 24 months to persons who were infected with both HIV-1 and HSV-2 and who had CD4 counts of 250 or more cells per cubic millimeter, did not reduce transmission of HIV-1 to sexual partners, despite significant reductions in plasma HIV-1 concentrations and in the incidence of genital ulcer disease caused by HSV-2. Thus, the lack of efficacy 


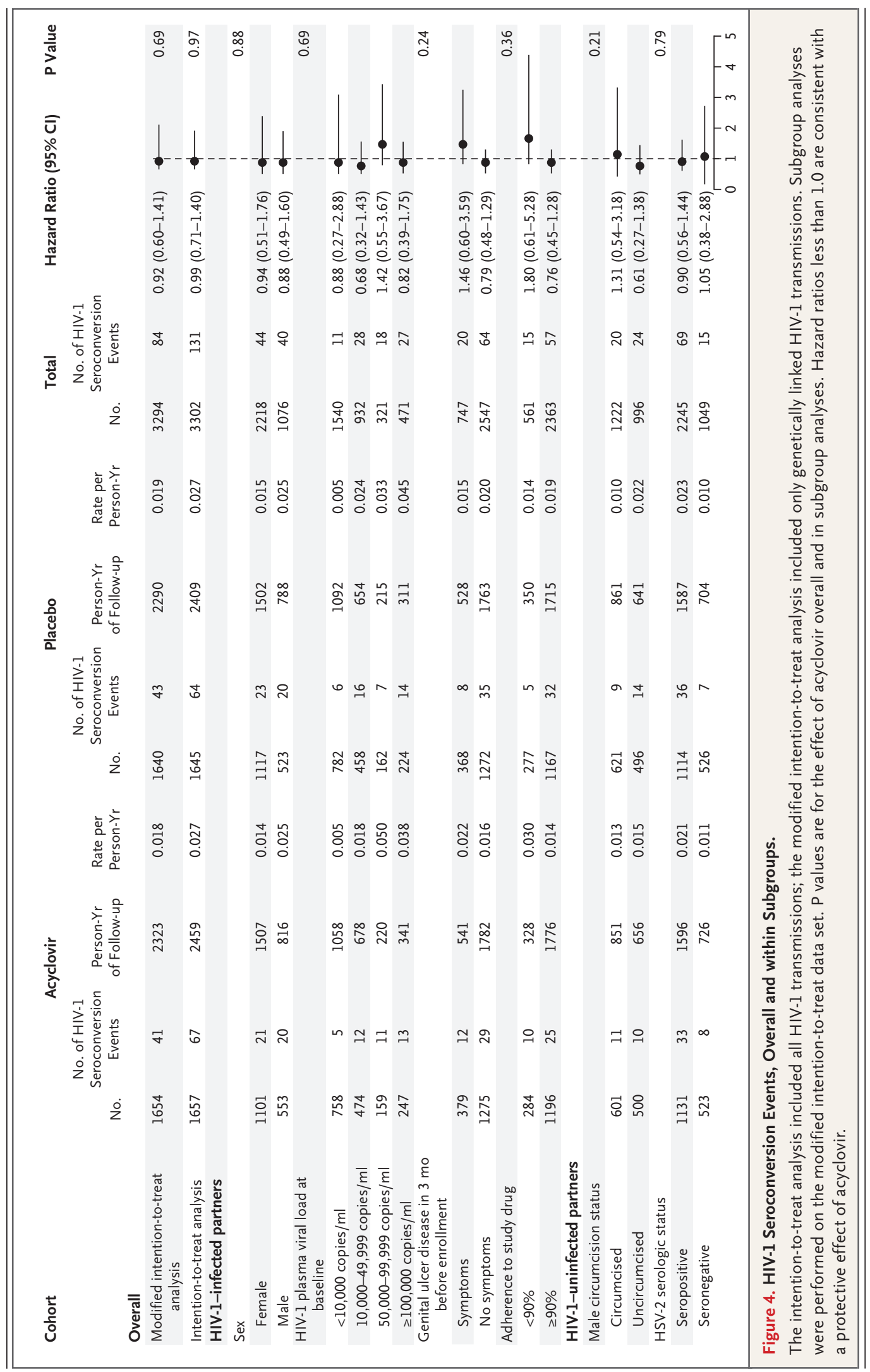


of HSV-2 suppressive therapy in preventing the transmission of HIV-1 among participants in this study does not appear to have been caused by poor activity of acyclovir against HSV-2 or by poor adherence to treatment, as assessed by monthly pill counts and by serum acyclovir testing in a subgroup of participants (Supplementary Appendix).

Epidemiologic and laboratory data accumulated over the course of more than 20 years suggest that genital HSV-2 infection increases the infectiousness of persons with HIV-1 infection. Genital ulcer disease increased female-to-male transmission of HIV-1 by a factor of nearly 5 among clients of female sex workers, ${ }^{23}$ and symptomatic genital ulcer disease in partners infected with HIV-1 increased the per-contact risk of HIV-1 transmission by a factor of 4 among monogamous HIV-1serodiscordant couples. ${ }^{14}$ Elevated HIV-1 levels in plasma and genital secretions have been associated with symptomatic and asymptomatic reactivation of genital HSV-2 infection. ${ }^{10-13,24}$ Moreover, in five placebo-controlled, randomized trials, plasma HIV-1 RNA levels were reduced by 0.25 to $0.5 \log _{10}$ copies per milliliter when persons who were infected with both HIV-1 and HSV-2 but were not receiving antiretroviral therapy received standard doses of HSV-2 suppressive agents (valacyclovir at a dose of $500 \mathrm{mg}$ twice daily or acyclovir at a dose of 400 to $800 \mathrm{mg}$ twice daily) for 1 to 3 months. ${ }^{4,5,15-17}$ Although the effects of acyclovir therapy on HIV-1 replication were thought to be indirectly mediated through HSV-2, two recent in vitro studies suggest that acyclovir may also have direct activity in reducing the replication of HIV-1. ${ }^{25,26}$

We selected acyclovir and the 400-mg twicedaily dose for our study on the basis of the similar efficacy of acyclovir at this dose to a dose of $500 \mathrm{mg}$ of valacyclovir twice daily in reducing symptomatic genital ulcer disease and asymptomatic reactivation of genital $\mathrm{HSV}-2^{27}$ and on the basis of the availability of acyclovir in a low-cost generic formulation. In addition, the reductions in plasma HIV-1 levels observed with this dose of acyclovir are similar to those seen with valacyclovir when it is used to suppress HSV-2 infection in persons infected with both HIV-1 and HSV-2., $4,5,15-17$ The reduction in plasma HIV-1 levels that we observed was similar to that seen in previous studies; therefore, the lack of efficacy in reducing the transmission of HIV-1 does not appear to have been due to lack of adherence to treatment or to

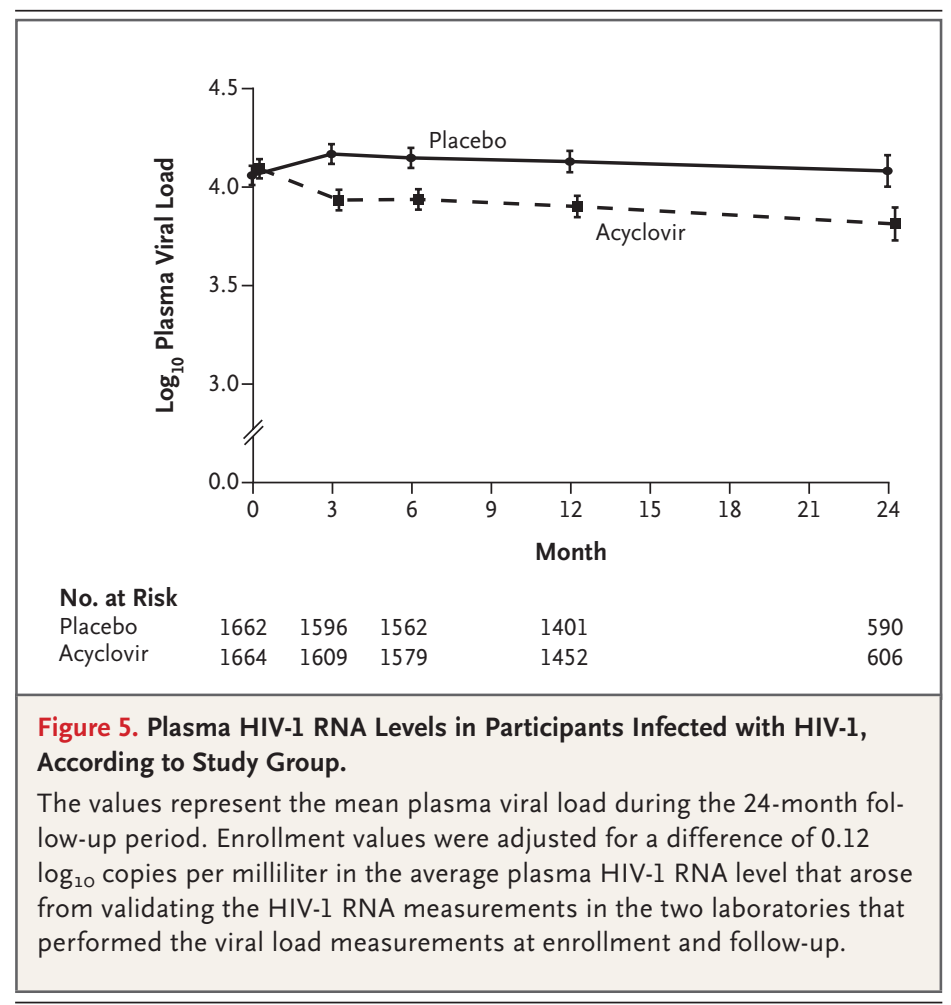

the formulation of the study drug, nor is it likely that the efficacy would have been improved if standard doses of valacyclovir rather than acyclovir had been used.

The lack of efficacy of acyclovir in reducing the transmission of HIV-1 in our study suggests that a greater reduction in HIV-1 levels is needed to reduce the risk of transmission. This indication that a greater reduction in the plasma viral load may have to be achieved provides information that can be useful in the development of other biomedical strategies for the prevention of HIV-1, such as the treatment of coexisting infections (e.g., malaria or helminthic infection), and in the development of HIV-1 vaccines directed at reducing the HIV-1 viral load. ${ }^{28,29}$

Most transmissions of HIV-1 infection in Africa are thought to occur within stable, cohabiting HIV-1-serodiscordant couples. ${ }^{30}$ Our study shows the feasibility of conducting trials involving such couples $^{18,31}$ to directly evaluate the efficacy of preventive strategies in decreasing the infectiousness of persons infected with HIV-1. The rate of HIV-1 transmission in our study population was 2.7 cases per 100 person-years overall, which is substantially lower than the rate in previous observational studies of HIV-1-serodiscordant cou- 
ples. $^{32,33}$ It is likely that the lower rate in our study was due largely to our having provided monthly counseling on risk reduction, free condoms, and other preventive services. Since approximately $30 \%$ of HIV-1 transmissions in this cohort of stable, cohabiting couples were attributable to outside partnerships, couples in which one of the partners is seropositive and the other is seronegative for HIV-1 should be counseled on potential misconceptions about the risk from sexual activity with other partners whose HIV-1 status is unknown.

In summary, our study of heterosexual HIV-1serodiscordant couples showed that among the partners who were infected with both HIV-1 and HSV-2 and who had CD4 counts of 250 or more cells per cubic millimeter, treatment with standard doses of acyclovir for the suppression of HSV-2 infection did not decrease the incidence of transmission of HIV-1 to the uninfected partners, despite significant reductions in plasma HIV-1 levels and in the incidence of genital ulcer disease. New strategies to reduce the risk of transmission of HIV-1 are needed for HIV-1-serodiscordant couples.

Supported by a grant (26469) from the Bill and Melinda Gates Foundation. HIV-1 RNA testing and some computational analyses were also supported by a grant (AI-27757) from the University of Washington Center for AIDS Research Clinical Retrovirology and Computational Biology Cores. Roche HIV-1 RNA quality-assessment panels were obtained under the auspices of the University of Washington AIDS Clinical Trials Group Virology Support Laboratory (AI-38858). Herpes laboratory support was provided in part through a grant (NIAID P01 AI30731) from the Herpes Program Project. Dr. Whittington received support from Gen-Probe to undertake testing for this project. The community outreach recruitment strategy used by some sites was adapted from the Influence Network Agent model developed by Emory collaborators under a grant (NIMH R01 MH66767) from the National Institute of Mental Health, and the couples' voluntary HIV counseling and testing procedures were based on the CDC/NIMH/Liverpool School of Tropical Medicine procedure manual, which was developed in part through support from a grant (R01 MH66767) from the NIMH.

Dr. Celum reports receiving grant support from and serving on an advisory board for GlaxoSmithKline; Dr. Wald, receiving consulting fees from Immune Design, AiCuris, Astellas Pharma US, and MediGene and speaking fees from Merck Vaccines; Dr. Fife, receiving grant support from Astellas Pharma US and GlaxoSmithKline; Dr. Coombs, serving on an advisory board for Merck; Dr. Morrow, serving on an advisory board for Abbott Molecular, Biokit USA, and Roche Diagnostics; Dr. Whittington, receiving grant support from Cepheid; Dr. Ronald, receiving lecture fees from Merck; Dr. Essex, receiving royalties from Harvard University for use of the HIV gp 120/160 protein for diagnostics; and Dr. Corey, receiving consulting fees from AiCuris and GenPhar, receiving fees and equity shares $(<1 \%$ ownership) for heading the scientific advisory board of Immune Design, and being named as a coinventor on several patents describing antigens and epitopes to which T-cell responses to HSV2 are directed. The University of Washington Virology Division Laboratories have received grant funding from GlaxoSmithKline and Novartis to perform serologic assays for herpes simplex virus and polymerase-chain-reaction assays for studies funded by the companies; Dr. Corey directs these laboratories but receives no salary support from these grants. No other potential conflicts of interest relevant to this article were reported.

We thank the couples who participated in this study and the referral partners, community advisory groups, institutions, and communities that collaborated with the study sites; the members of the data safety and monitoring board (Drs. Richard Whitley [chair], Ann Arvin, Francis Kasolo, Alejandros Llanos, Jonathan Matenga, James Neaton, and David Serwadda) for their oversight and expertise; the members of the Endpoint Adjudication Committee (Drs. Jan Albert, Thomas Leitner, and Francine McCutchan) for their expertise and time in reviewing sequencing data and determining linkages; Toni Maddox for assistance with the preparation of an earlier version of the manuscript; and Drs. Deborah Donnell and Patrick Ndase for their contributions to the study and insightful comments on the analysis and on an earlier version of the manuscript.

\section{APPENDIX}

The authors' full names and degrees are as follows: Connie Celum, M.D., M.P.H., Anna Wald, M.D., M.P.H., Jairam R. Lingappa, M.D., Ph.D., Amalia S. Magaret, Ph.D., Richard S. Wang, M.S., Nelly Mugo, M.B., Ch.B., M.P.H., Andrew Mujugira, M.B., Ch.B., M.Sc., Jared M. Baeten, M.D., Ph.D., James I. Mullins, Ph.D., James P. Hughes, Ph.D., Elizabeth A. Bukusi, M.B., Ch.B., Ph.D., Craig R. Cohen, M.D., M.P.H., Elly Katabira, M.B., Ch.B., Allan Ronald, M.D., James Kiarie, M.B., Ch.B., M.P.H., Carey Farquhar, M.D., M.P.H., Grace John Stewart, M.D., Ph.D., Joseph Makhema, M.B., Ch.B., Myron Essex, D.V.M., Ph.D., Edwin Were, M.B., Ch.B., M.P.H., Kenneth H. Fife, M.D., Ph.D., Guy de Bruyn, M.B., B.Ch., M.P.H., Glenda E. Gray, M.B., B.Ch., James A. McIntyre, M.B., B.Ch., Rachel Manongi, M.D., Saidi Kapiga, M.D., Sc.D., David Coetzee, M.B., B.Ch., Susan Allen, M.D., M.P.H., Mubiana Inambao, M.D., M.P.H., Kayitesi Kayitenkore, M.D., Etienne Karita, M.D., M.Sc., William Kanweka, M.D., M.P.H., Sinead Delany, M.D., Ph.D., Helen Rees, M.B., B.S., Bellington Vwalika, M.D., M.Sc., Wendy Stevens, M.B., B.Ch., Mary S. Campbell, M.D., Katherine K. Thomas, M.S., Robert W. Coombs, M.D., Ph.D., Rhoda Morrow, Ph.D., William L.H. Whittington, A.B., M. Juliana McElrath, M.D., Ph.D., Linda Barnes, M.H.A., Renee Ridzon, M.D., and Lawrence Corey, M.D.

The authors' affiliations are as follows: the Departments of Global Health (C.C., J.R.L., R.S.W., N.M., A.M., J.M.B., E.A.B., G.J.S., M.J.M., L.B.), Epidemiology (C.C., A.W., C.F., G.J.S.), Medicine (C.C., A.W., J.R.L., J.M.B., J.I.M., C.F., G.J.S., M.S.C., K.K.T., R.W.C., W.L.H.W., M.J.M., L.C.), Laboratory Medicine (A.W., A.S.M., J.I.M., R.W.C., R.M., L.C.), Microbiology (J.I.M.), Pediatrics (J.R.L.), and Biostatistics (J.P.H.), University of Washington; Vaccine and Infectious Disease Institute, Fred Hutchinson Cancer Research Center (A.W., A.S.M., M.J.M., L.C.); and the Bill and Melinda Gates Foundation (R.R.) - all in Seattle; the Department of Obstetrics and Gynecology, University of Nairobi and Kenyatta National Hospital (N.M., E.A.B., J.K.); and the Center for Microbiology Research, Kenya Medical Research Institute (E.A.B.) — both in Nairobi; and the Department of Reproductive Health, Moi University, Eldoret (E.W.) - all in Kenya; the Department of Obstetrics, Gynecology and Reproductive Sciences, University of California, San Francisco, San Francisco (C.R.C.); the Infectious Disease Institute, Makerere University, Kampala, Uganda (E.K.); the Department of Medicine, University of Manitoba, Winnipeg, Canada (A.R.); Botswana-Harvard Partnership, Gaborone, Botswana (J.M.); the Department of Immunology and Infectious Diseases, Harvard School of Public Health, Harvard University, Boston (M.E.); the Department of Medicine, Indiana Univer- 
sity, Indianapolis (K.H.F.); the Perinatal HIV Research Unit (G.B., G.E.G., J.A.M.), Reproductive Health and HIV Research Unit (S.D., H.R.); and Contract Laboratory Services (W.S.) - all at the University of the Witwatersrand, Johannesburg; and the Infectious Disease Epidemiology Unit, University of Cape Town, Cape Town (D.C.) - all in South Africa; Kilimanjaro Christian Medical Centre, Moshi, Tanzania (R.M., S.K.); the Department of Epidemiology and Population Health, London School of Hygiene and Tropical Medicine, London (S.K.); the Rwanda-Zambia HIV Research Group and Emory University Schools of Medicine and Public Health, Atlanta (S.A., M.I., K.K., E.K., W.K., B.V.).

\section{REFERENCES}

1. Weiss H. Epidemiology of herpes simplex virus type 2 infection in the developing world. Herpes 2004;11:Suppl 1:24A35A.

2. Siegal FP, Lopez C, Hammer GS, et al. Severe acquired immunodeficiency in male homosexuals, manifested by chronic perianal ulcerative herpes simplex lesions. N Engl J Med 1981;305:1439-44.

3. Strick LB, Wald A, Celum C. Management of herpes simplex virus type 2 infection in HIV type 1-infected persons. Clin Infect Dis 2006;43:347-56.

4. Zuckerman RA, Lucchetti A, Whittington WL, et al. Herpes simplex virus (HSV) suppression with valacyclovir reduces rectal and blood plasma HIV-1 levels in HIV-1/ HSV-2-seropositive men: a randomized, double-blind, placebo-controlled crossover trial. J Infect Dis 2007;196:1500-8.

5. Baeten JM, Strick LB, Lucchetti A, et al. Herpes simplex virus (HSV)-suppressive therapy decreases plasma and genital HIV-1 levels in HSV-2/HIV-1 coinfected women: a randomized, placebo-controlled, cross-over trial. J Infect Dis 2008;198: 1804-8.

6. Kucera LS, Leake E, Iyer N, Raben D, Myrvik QN. Human immunodeficiency virus type 1 (HIV-1) and herpes simplex virus type 2 (HSV-2) can coinfect and simultaneously replicate in the same human CD4+ cell: effect of coinfection on infectious HSV-2 and HIV-1 replication. AIDS Res Hum Retroviruses 1990;6:641-7.

7. Diaz JJ, Dodon MD, Schaerer-Uthurralt $\mathrm{N}$, et al. Post-transcriptional transac tivation of human retroviral envelope glycoprotein expression by herpes simplex virus Us11 protein. Nature 1996;379:273-7. 8. Heng MC, Heng SY, Allen SG. Co-infection and synergy of human immunodeficiency virus-1 and herpes simplex virus-1. Lancet 1994;343:255-8.

9. Mosca JD, Bednarik DP, Raj NB, et al. Herpes simplex virus type-1 can reactivate transcription of latent human immunodeficiency virus. Nature 1987;325:67-70. 10. Schacker T, Ryncarz AJ, Goddard J, Diem K, Shaughnessy M, Corey L. Frequent recovery of HIV-1 from genital herpes simplex virus lesions in HIV-1-infected men. JAMA 1998;280:61-6.

11. Schacker T, Zeh J, Hu H, Shaughnessy $\mathrm{M}$, Corey L. Changes in plasma human immunodeficiency virus type 1 RNA as- sociated with herpes simplex virus reactivation and suppression. J Infect Dis 2002; 186:1718-25.

12. Mbopi-Kéou F-X, Grésenguet G, Mayaud $\mathrm{P}$, et al. Interactions between herpes simplex virus type 2 and human immunodeficiency virus type 1 infection in African women: opportunities for intervention. J Infect Dis 2000;182:1090-6.

13. Baeten JM, McClelland RS, Corey L, et al. Vitamin A supplementation and genital shedding of herpes simplex virus among HIV-1-infected women: a randomized clinical trial. J Infect Dis 2004;189:1466-71.

14. Gray RH, Wawer MJ, Brookmeyer R, et al. Probability of HIV-1 transmission per coital act in monogamous, heterosexual, HIV-1-discordant couples in Rakai, Uganda. Lancet 2001;357:1149-53.

15. Nagot N, Ouédraogo A, Foulongne V, et al. Reduction of HIV-1 RNA levels with therapy to suppress herpes simplex virus. N Engl J Med 2007;356:790-9.

16. Dunne EF, Whitehead S, Sternberg M, et al. Suppressive acyclovir therapy reduces HIV cervicovaginal shedding in HIVand HSV-2-infected women, Chiang Rai, Thailand. J Acquir Immune Defic Syndr 2008;49:77-83.

17. Delany S, Mlaba N, Clayton T, et al. Impact of aciclovir on genital and plasma HIV-1 RNA in HSV-2/HIV-1 co-infected women: a randomized placebo-controlled trial in South Africa. AIDS 2009;23:461-9. 18. Lingappa JR, Kahle E, Mugo N, et al. Characteristics of HIV-1 discordant couples enrolled in a trial of HSV-2 suppression to reduce HIV-1 transmission: the Partners Study. PLoS One 2009;4(4):e5272. 19. Lan KKG, DeMets DL. Discrete sequential boundaries for clinical trials. Biometrika 1983;70:659-63.

20. O'Brien PC, Fleming TR. A multiple testing procedure for clinical trials. Biometrics 1979;35:549-56.

21. Laird NM, Ware JH. Random-effects models for longitudinal data. Biometrics 1982;38:963-74.

22. Glynn JR, Biraro S, Weiss HA. Herpes simplex virus type 2: a key role in HIV incidence. AIDS 2009;23:1595-8.

23. Cameron DW, Simonsen JN, D'Costa LJ, et al. Female to male transmission of human immunodeficiency virus type 1 : risk factors for seroconversion in men. Lancet 1989;2:403-7.
24. Mole L, Ripich S, Margolis D, Holodniy $M$. The impact of active herpes simplex virus infection on human immunodeficiency virus load. J Infect Dis 1997; 176:766-70.

25. Lisco A, Vanpouille C, Tchesnokov EP, et al. Acyclovir is activated into a HIV-1 reverse transcriptase inhibitor in herpesvirus-infected human tissues. Cell Host Microbe 2008;4:260-70.

26. McMahon MA, Siliciano JD, Lai J, et al. The antiherpetic drug acyclovir inhibits HIV replication and selects the V75I reverse transcriptase multidrug resistance mutation. J Biol Chem 2008;283:31289-93. 27. Gupta R, Wald A, Krantz E, et al. Valacyclovir and acyclovir for suppression of shedding of herpes simplex virus in the genital tract. J Infect Dis 2004;190:137481.

28. Walson JL, Otieno PA, Mbuchi M, et al. Albendazole treatment of HIV-1 and helminth co-infection: a randomized, double-blind, placebo-controlled trial. AIDS 2008;22:1601-9.

29. Gilbert PB, DeGruttola VG, Hudgens MG, Self SG, Hammer SM, Corey L. What constitutes efficacy for a human immunodeficiency virus vaccine that ameliorates viremia: issues involving surrogate end points in phase 3 trials. J Infect Dis 2003;188:179-93.

30. Dunkle KL, Stephenson R, Karita E, et al. New heterosexually transmitted HIV infections in married or cohabiting couples in urban Zambia and Rwanda: an analysis of survey and clinical data. Lancet 2008;371:2183-91.

31. Lingappa JR, Lambdin B, Bukusi EA, et al. Regional differences in prevalence of HIV-1 discordance in Africa and enrollment of HIV-1 discordant couples into an HIV-1 prevention trial. PLoS One 2008; 3(1):e1411.

32. Quinn TC, Wawer MJ, Sewankambo $\mathrm{N}$, et al. Viral load and heterosexual transmission of human immunodeficiency virus type 1. N Engl J Med 2000;342:921-9. 33. Fideli US, Allen SA, Musonda R, et al. Virologic and immunologic determinants of heterosexual transmission of human immunodeficiency virus type 1 in Africa. AIDS Res Hum Retroviruses 2001;17:90110.

Copyright (c) 2010 Massachusetts Medical Society. 